\title{
Transistor Device
}

National Cancer Institute

\section{Source}

National Cancer Institute. Transistor Device. NCI Thesaurus. Code C50228.

A semiconductor component with three terminals that is designed to amplify a signal. It is the fundamental component of all modern circuitry. 